\title{
Case Report \\ Exercise-Induced Pulmonary Edema in a Triathlon
}

\author{
Hirotomo Yamanashi, ${ }^{1}$ Jun Koyamatsu, ${ }^{1}$ Masaharu Nobuyoshi, ${ }^{1}$ \\ Kunihiko Murase, ${ }^{2}$ and Takahiro Maeda ${ }^{1}$ \\ ${ }^{1}$ Department of Island and Community Medicine, Nagasaki University Graduate School of Biomedical Science, \\ Goto, Nagasaki 853-8691, Japan \\ ${ }^{2}$ Goto Central Hospital, Yoshikugi, Goto, Nagasaki 853-8691, Japan
}

Correspondence should be addressed to Hirotomo Yamanashi; yamanashi@nagasaki-u.ac.jp

Received 13 May 2015; Accepted 25 June 2015

Academic Editor: Jagdish Butany

Copyright (C) 2015 Hirotomo Yamanashi et al. This is an open access article distributed under the Creative Commons Attribution License, which permits unrestricted use, distribution, and reproduction in any medium, provided the original work is properly cited.

Introduction. Family physicians have more opportunities to attend athletic competitions as medical staff at first-aid centers because of the increasing popularity of endurance sports. Case. A 38-year-old man who participated in a triathlon race experienced difficulty in breathing after swimming and was moved to a first-aid center. His initial oxygen saturation was $82 \%$ and a thoracic computed tomography scan showed bilateral ground glass opacity in the peripheral lungs. His diagnosis was noncardiogenic pulmonary edema associated with exercise or swimming: exercise-induced pulmonary edema (EIPE) or swimming-induced pulmonary edema (SIPE). Treatment with furosemide and corticosteroid relieved his symptoms of pulmonary edema. Discussion. Noncardiogenic pulmonary edema associated with endurance sports is not common, but knowledge about EIPE/SIPE or neurogenic pulmonary edema associated with hyponatremia, which is called Ayus-Arieff syndrome, is crucial. Knowledge and caution for possible risk factors, such as exposure to cold water or overhydration, are essential for both medical staff and endurance athletes. Conclusion. To determine the presence of pulmonary edema associated with strenuous exercise, oxygen saturation should be used as a screening tool at a first-aid center. To avoid risks for EIPE/SIPE, knowledge about these diseases is essential for medical staff and for athletes who perform extreme exercise.

\section{Introduction}

Family physicians frequently attend athletic competitions as medical assistants at first-aid centers because of the increasing popularity of endurance sports. Noncardiogenic pulmonary edema associated with exercise has been previously reported in various endurance athletes, including swimmers [1-4], divers [5,6], marathon runners [7], triathletes [8], and cyclists [9]. The mechanism of this condition is unclear [10], but cases are categorized into exercise-induced pulmonary edema (EIPE), swimming-induced pulmonary edema (SIPE), or neurogenic pulmonary edema associated with hyponatremia, which is also known as Ayus-Arieff syndrome [7, 11, 12]. The prognosis of EIPE/SIPE is generally good with a quick diagnosis and adequate treatment, whereas an unfavorable prognosis has been reported with neurogenic pulmonary edema [13].

\section{Case Presentation}

A 38-year-old man participated in a triathlon race, which consisted of $3.8 \mathrm{~km}$ of swimming, $180 \mathrm{~km}$ of cycling, and $42.2 \mathrm{~km}$ of running. Ambient and water temperatures were $20.0^{\circ} \mathrm{C}$ and $21.4^{\circ} \mathrm{C}$, respectively. Because he appeared to have difficulty in breathing during swimming, lifeguards moved him to the first-aid center shortly after he reached the coast. He had no relevant past medical or allergic history. He denied submersion injury or overt aspiration of seawater.

On physical examination, his consciousness was alert, blood pressure was $119 / 84 \mathrm{~mm} \mathrm{Hg}$, respiratory rate was 14 breaths/min, and initial oxygen saturation was $82 \%$ at room air. A respiratory examination showed bilateral wheezing with forced breathing. A standby ambulance quickly delivered him to the nearby hospital. Remarkable findings included bilateral ground glass opacity in the peripheral 


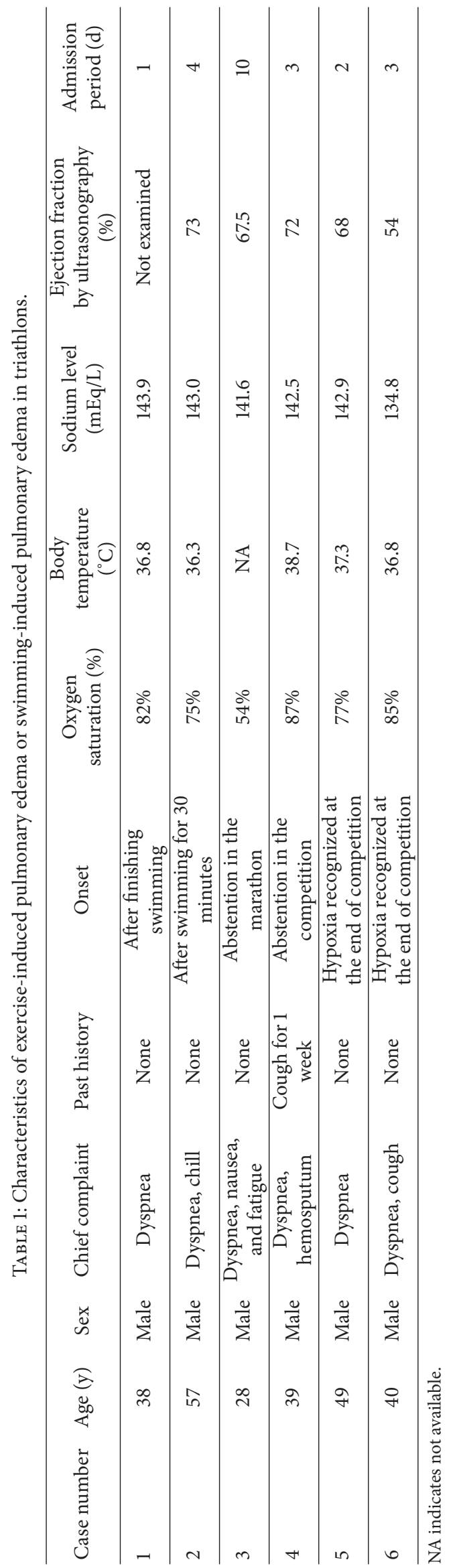


lungs on a thoracic computed tomography scan. A laboratory examination showed a serum sodium level of $143.9 \mathrm{mEq} / \mathrm{L}$ and B-type natriuretic peptide level of $11.5 \mathrm{pg} / \mathrm{mL}$.

We diagnosed this case as EIPE/SIPE because there was no elevation in cardiac enzymes, with a normal electrocardiogram after consideration of the possibility of neurogenic pulmonary edema associated with hyponatremia or cardiogenic pulmonary edema. We treated him with methylprednisolone and furosemide intravenously. All symptoms of pulmonary edema, including dyspnea and hypoxemia, resolved within 4.5 hours, and he was discharged the same day without recurrence.

We have experienced six EIPE/SIPE cases at a triathlon race over a decade (Table 1). Among six men (age: 2857 years), all completely recovered shortly after admission (admission period: 1-10 days), except for one patient who needed mechanical ventilation. Chest X-rays showed diffuse consolidation in all of the patients. Hyponatremia was not observed in any patients.

\section{Discussion}

The mechanism of EIPE/SIPE is not well known, but stress failure of pulmonary capillaries likely plays a major role in development of pulmonary edema in scuba divers and swimmers [1-6]. Constriction of peripheral blood vessels caused by exposure to a cold environment to maintain a core temperature leads to central pooling of blood. This leads to increased preload, pulmonary artery pressure, and cardiac output, resulting in a rise in pulmonary capillary pressure. Excessive drinking of water to counteract dehydration also causes an increase in preload and pulmonary capillary pressure. These physiological responses appear to cause failure of pulmonary capillaries and contribute to development of acute pulmonary edema.

Knowledge on EIPE/SIPE is essential for relevant medical staff and endurance athletes. A pulse oximeter should be actively used as an available screening tool to detect EIPE/SIPE at the first-aid center. However, the initial presentation of EIPE/SIPE is difficult to distinguish from cardiogenic pulmonary edema or Ayus-Arieff syndrome without biochemical investigations at a first-aid center. Therefore, medical personnel should quickly detect hypoxic patients, and further assessment should be performed at a hospital. To avoid risks for EIPE/SIPE, knowledge on factors contributing to development of pulmonary edema, such as exposure to a cold environment and excessive drinking of water, is essential $[14,15]$. Careful instructions should be provided to participants in endurance sports because one study reported recurrent SIPE episodes as high as 22.9\% [2].

\section{Conclusion}

To rapidly manage patients with potential critical pulmonary edema associated with strenuous exercise, initial assessment of hypoxia is important in the setting of a first-aid center. To avoid risks for EIPE/SIPE, knowledge of these diseases is essential for relevant medical staff and for athletes who perform extreme exercise.

\section{Ethical Approval}

The study was conducted in accordance with the Declaration of Helsinki and Good Clinical Practices.

\section{Conflict of Interests}

The authors declare that there is no conflict of interests regarding the publication of this paper.

\section{References}

[1] A. Shupak, D. Weiler-Ravell, Y. Adir, Y. I. Daskalovic, Y. Ramon, and D. Kerem, "Pulmonary oedema induced by strenuous swimming: A field study," Respiration Physiology, vol. 121, no. 1, pp. 25-31, 2000.

[2] Y. Adir, A. Shupak, A. Gil et al., "Swimming-induced pulmonary edema: clinical presentation and serial lung function," Chest, vol. 126, no. 2, pp. 394-399, 2004.

[3] D. Weiler-Ravell, A. Shupak, I. Goldenberg et al., "Pulmonary oedema and haemoptysis induced by strenuous swimming," British Medical Journal, vol. 311, no. 7001, pp. 361-362, 1995.

[4] R. Biswas, P. K. Shibu, and C. M. James, "Pulmonary oedema precipitated by cold water swimming," British Journal of Sports Medicine, vol. 38, no. 6, p. e36, 2004.

[5] J. B. Slade Jr., T. Hattori, C. S. Ray, A. A. Bove, and P. Cianci, "Pulmonary edema associated with scuba diving: case reports and review," Chest, vol. 120, no. 5, pp. 1686-1694, 2001.

[6] M. Pons, D. Blickenstorfer, E. Oechslin et al., "Pulmonary oedema in healthy persons during scuba-diving and swimming," European Respiratory Journal, vol. 8, no. 5, pp. 762-767, 1995.

[7] J. C. Ayus, J. Varon, and A. I. Arieff, "Hyponatremia, cerebral edema, and noncardiogenic pulmonary edema in marathon runners," Annals of Internal Medicine, vol. 132, no. 9, pp. 711-714, 2000.

[8] J. L. G. Ma and M. J. Dutch, "Extreme sports: extreme physiology. Exercise-induced pulmonary oedema," Emergency Medicine Australasia, vol. 25, no. 4, pp. 368-371, 2013.

[9] D. C. McKenzie, T. J. O’Hare, and J. Mayo, “The effect of sustained heavy exercise on the development of pulmonary edema in trained male cyclists," Respiratory Physiology and Neurobiology, vol. 145, no. 2-3, pp. 209-218, 2005.

[10] A. N. H. Hodges, J. R. Mayo, and D. C. McKenzie, "Pulmonary oedema following exercise in humans," Sports Medicine, vol. 36, no. 6, pp. 501-512, 2006.

[11] K. Kalantar-Zadeh, M. K. Nguyen, R. Chang, and I. Kurtz, "Fatal hyponatremia in a young woman after ecstasy ingestion," Nature Clinical Practice Nephrology, vol. 2, no. 5, pp. 283-288, 2006.

[12] M. L. Moritz and J. C. Ayus, "Exercise-associated hyponatremia: why are athletes still dying?" Clinical Journal of Sport Medicine, vol. 18, no. 5, pp. 379-381, 2008.

[13] J. C. Ayus and A. I. Arieff, "Pulmonary complications of hyponatremic encephalopathy: noncardiogenic pulmonary edema and hypercapnic respiratory failure," Chest, vol. 107, no. 2, pp. 517-521, 1995. 
[14] J. B. West, O. Mathieu-Costello, J. H. Jones et al., "Stress failure of pulmonary capillaries in racehorses with exercise-induced pulmonary hemorrhage," Journal of Applied Physiology, vol. 75, no. 3, pp. 1097-1109, 1993.

[15] W. Schaffartzik, J. Arcos, K. Tsukimoto, O. Mathieu-Costello, and P. D. Wagner, "Pulmonary interstitial edema in the pig after heavy exercise," Journal of Applied Physiology, vol. 75, no. 6, pp. 2535-2540, 1993. 


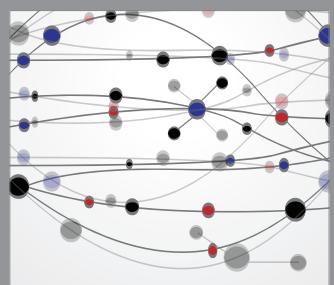

The Scientific World Journal
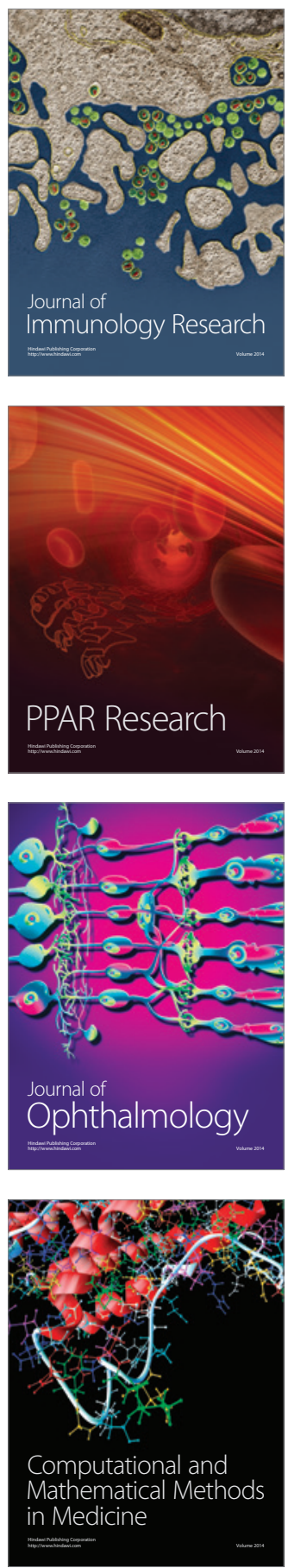

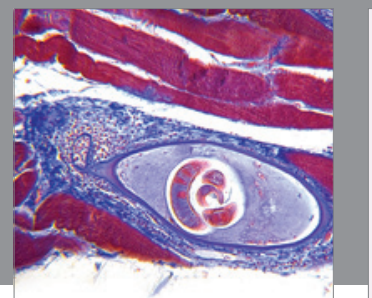

Gastroenterology

Research and Practice
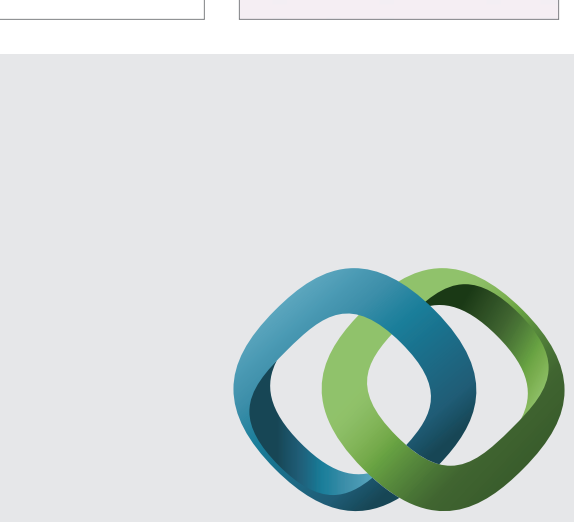

\section{Hindawi}

Submit your manuscripts at

http://www.hindawi.com
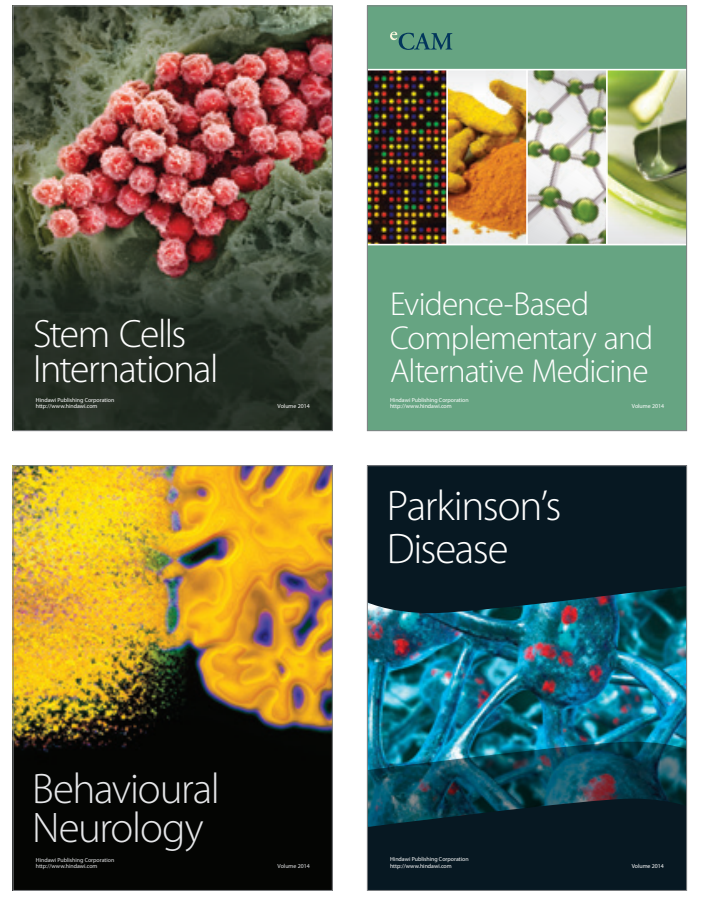
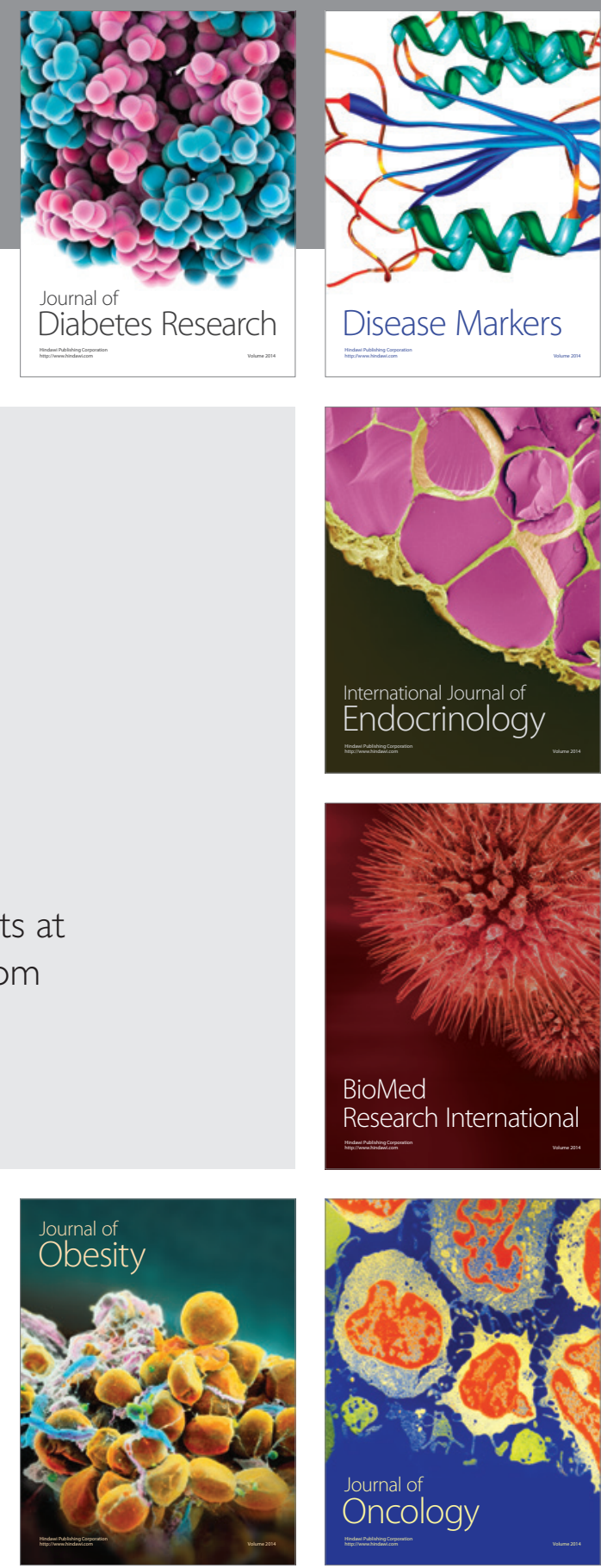

Disease Markers
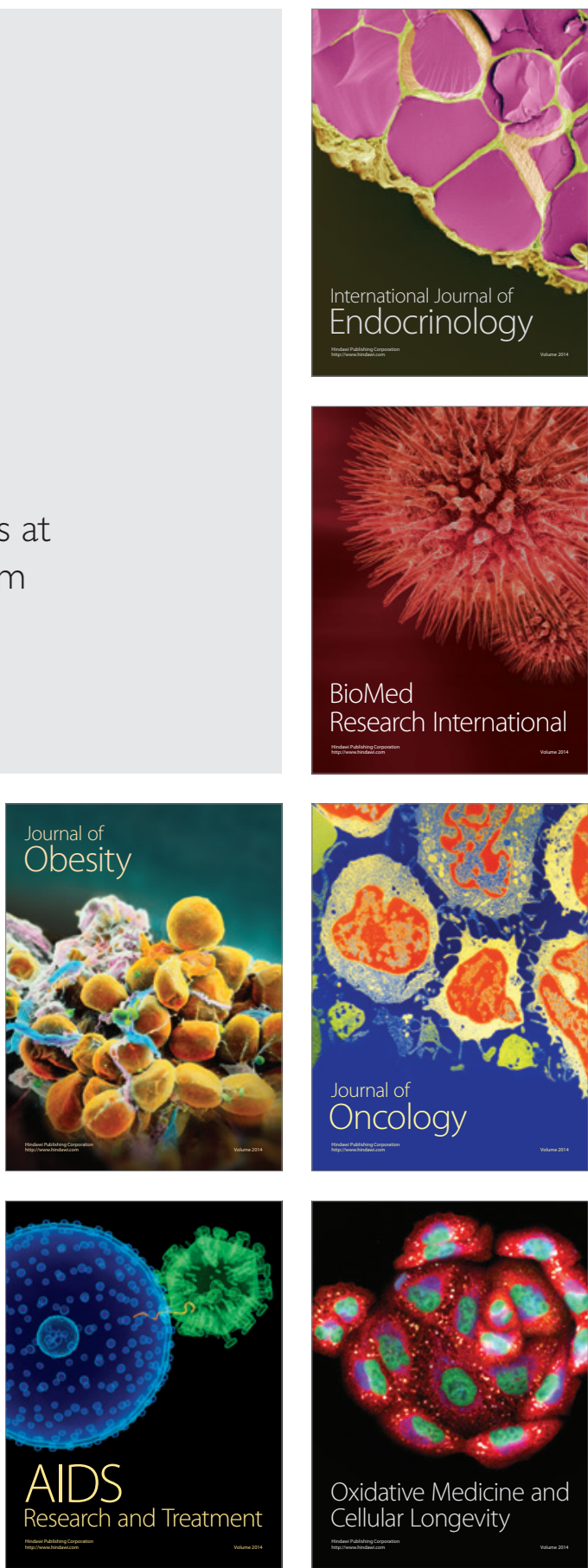